\title{
Karyological Study of the Jungle Cat, Felis chaus (Carnivora, Felidae) by Conventional Staining, G- banding and High-resolution Staining Technique
}

\author{
Alongkoad Tanomtong ${ }^{1, *}$, Sumpars Khunsook ${ }^{1}$, Puntivar Keawmad ${ }^{1}$ \\ and Pornnarong Siripiyasing ${ }^{2}$ \\ ${ }^{1}$ Genetics Program, Department of Biology, Faculty of Science, Khon Kaen University, \\ Muang, Khon Kaen 40002, Thailand \\ ${ }^{4}$ Major of Biology, Faculty of Science and Technology, Mahasarakham Rajabhat University, \\ Muang, Mahasarakham 44000, Thailand
}

Received December 3, 2007; accepted April 3, 2008

\begin{abstract}
Summary As an endangered species in Thailand, wild animal species of the jungle cat (Felis chaus) was selected for karyological study. Blood samples were taken from 2 males and 2 females. After the standard whole blood lymphocyte culture in the presence of colchicine, the metaphase spreads were performed on microscopic slides and air-dried. Conventional staining, G-banding and high-resolution staining technique were applied to stain the chromosomes. The results showed that $2 n$ (diploid) of jungle cat was 38 , and the fundamental number (NF) was 72 in the male and female. There are 6 autosome types: A type had 6 large submetacentric chromosomes, B type had 8 large acrocentric chromosomes, $\mathrm{C}$ type had 4 large metacentric chromosomes, D type had 8 small submetacentric chromosomes, E type had 6 small metacentric chromosomes and $\mathrm{F}$ type had 4 small telocentric chromosomes. A pair of the short arm of chromosome E1 (chromosome pairs 14) showed a clearly observable satellite chromosomes. The $\mathrm{X}$ chromosome was medium submetacentric chromosome and the Y chromosome was the smallest submetacentric chromosome. From the G-banding and high-resolution staining technique, the number of bands and locations in the jungle cat was 167 and 183 respectively, and each chromosome pair could be clearly differentiated. We found that chromosomes B1, B2, D1, D4, E3, F2 and X chromosome patterns were according to the domestic cat (Felis catus) chromosomes. Chromosomes A1, A2, A3, B3, B4, C1, C2, D2, E1, E2, F1 and Y-chromosome are similar to those of the domestic cat. These results show the evolutionary relationship between the jungle cat and domestic cat. The karyotype formula for the male and female jungle cat is as follows: $2 n(38)=\mathrm{L}_{4}{ }^{\mathrm{m}}+\mathrm{L}_{6}{ }^{\mathrm{sm}}+\mathrm{L}_{8}{ }^{\mathrm{a}}+\mathrm{S}_{6}{ }^{\mathrm{m}}+\mathrm{S}_{8}{ }^{\mathrm{sm}}+\mathrm{S}_{4}^{\mathrm{t}}+$ sex chromosomes.
\end{abstract}

Key words Karyotype, Jungle cat (Felis chaus), Chromosome

Thailand is a country with high biodiversity, resulting from its varying ecosystem and forests. It has been estimated that there may be up to 100,000 wildlife species in Thailand as well as many unknown plant species. Unfortunately, rushed economic development and social welfare has led to vast destruction of Thailand's forests and wildlife resources. Many wildlife species have become extinct due to loss of habitat, hunting for food, trade and export. One such example is jungle cat (Felis chaus), whose number are rapidly deteriorating. Their present rarity causes great difficulty in obtaining blood samples for cytogenetic studies as well.

The Jungle cat is a member of the family Felidae. The family has only 9 species of 6 genera in Thailand (Lekagul and McNeely 1977, 1988, Par et al. 2003). The jungle cat is a small wild cat that is widespread throughout Asia, from the delta of the Volga River south to Palestine, east through India, Nepal and Burma to Thailand and Indochina. The common characteristics of the jungle cat

\footnotetext{
*Corresponding author, e-mail: tanomtong@hotmail.com
} 
are: the pelage varies from light ashy gray to yellowish brown, with the hair of the under parts lighter and longer. It lacks stripes or spots on the body, but there are two bars on the inner side of the forelimbs and numerous bars and spots on the outside of all four legs (Lekagul and McNeely 1977, 1988) (Fig. 1).

There are several reports on cytogenetic studies of the family Felidae included Makino and Tateishi (1952), Thuline and Norby (1961), Ohno et al. (1962), Hsu et al. (1963), Matano (1963), Chu et al. (1964), Hus and Rearden (1965), Benirschke and Low (1966), Leyhausen and Tonkin (1968), Sutton (1968), Wurster and Benirschke (1967, 1968a, 1968b), Hard (1968), Wurster (1969), Milosevic et al. (1972), Wurster-Hill (1973), Wurster-Hill and Meritt (1974), Yang et al. (2000), Nie et al. (2002), and Keawmad et al. (2007). Our knowledge, cytogenetic study of the jungle cat,

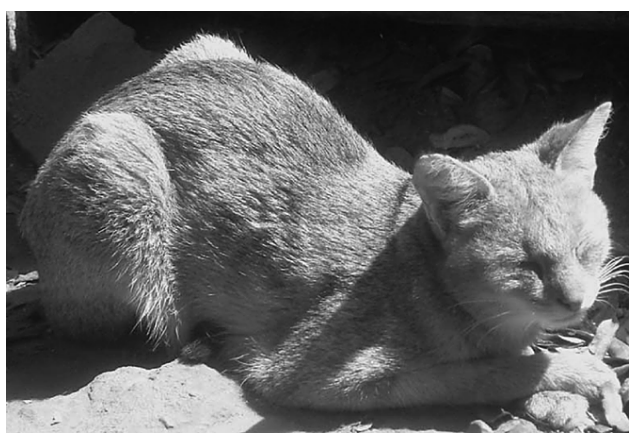

Fig. 1. The jungle cat, Felis chaus Guldenstaedt, 1776 (Carnivora, Felidae)
Felis chaus (Carnivora, Felidae), can be a useful information for the conservation of family Felidae in Thailand.

\section{Materials and methods}

Blood samples of 2 males and 2 females jungle cats were collected from Songkla Zoo, Thailand and then applied for cytogenetic studies by lymphocyte culture of whole blood samples. The culture cells were treated with a colchicine-hypotonic-fixation-air-drying technique followed by conventional staining, Gbanding and high-resolution staining tech-

Table 1. Mean of length short arm chromosome (Ls), length long arm chromosome (L1), length total arm chromosome (LT), relative length (RL) centromeric index (CI) and standard deviation (SD) of RL, CI from metaphase chromosome of 10 cells in the female jungle cat (Felis chaus Guldenstaedt, 1776) $2 n$ (diploid) $=38$

\begin{tabular}{cccccccc}
\hline \hline $\begin{array}{c}\text { Chromosome } \\
\text { pairs }\end{array}$ & Ls & L1 & LT & CI \pm SD & RL \pm SD & $\begin{array}{c}\text { Chromosome } \\
\text { size }\end{array}$ & $\begin{array}{c}\text { Chromosome } \\
\text { type }\end{array}$ \\
\hline A1 & 0.580 & 1.014 & 1.594 & $0.636 \pm 0.016$ & $0.086 \pm 0.003$ & $\mathrm{~L}$ & $\begin{array}{c}\text { Submetacentric } \\
\text { A2 }\end{array}$ \\
A3 & 0.480 & 0.809 & 1.289 & $0.628 \pm 0.030$ & $0.070 \pm 0.009$ & $\mathrm{~L}$ & $\begin{array}{c}\text { Submetacentric } \\
\text { B1 }\end{array}$ \\
B2 & 0.396 & 0.645 & 1.041 & $0.620 \pm 0.028$ & $0.052 \pm 0.005$ & $\mathrm{~L}$ & Submetacentric \\
B3 & 0.353 & 0.871 & 1.224 & $0.712 \pm 0.008$ & $0.066 \pm 0.005$ & $\mathrm{~L}$ & Acrocentric \\
B4 & 0.337 & 0.809 & 1.146 & $0.706 \pm 0.010$ & $0.062 \pm 0.005$ & $\mathrm{~L}$ & Acrocentric \\
C1 & 0.312 & 0.730 & 1.042 & $0.701 \pm 0.005$ & $0.055 \pm 0.004$ & $\mathrm{~L}$ & Acrocentric \\
C2 & 0.706 & 0.751 & 1.457 & $0.515 \pm 0.010$ & $0.079 \pm 0.006$ & $\mathrm{~L}$ & Metacentric \\
D1 & 0.504 & 0.612 & 1.116 & $0.548 \pm 0.020$ & $0.060 \pm 0.004$ & $\mathrm{~L}$ & Metacentric \\
D2 & 0.298 & 0.499 & 0.797 & $0.626 \pm 0.011$ & $0.049 \pm 0.003$ & $\mathrm{~S}$ & Submetacentric \\
D3 & 0.290 & 0.491 & 0.781 & $0.614 \pm 0.019$ & $0.045 \pm 0.003$ & $\mathrm{~S}$ & Submetacentric \\
D4 & 0.300 & 0.478 & 0.778 & $0.614 \pm 0.015$ & $0.042 \pm 0.002$ & $\mathrm{~S}$ & Submetacentric \\
E1 & 0.267 & 0.436 & 0.703 & $0.620 \pm 0.018$ & $0.038 \pm 0.002$ & $\mathrm{~S}$ & Submetacentric \\
E2 & 0.367 & 0.429 & 0.796 & $0.539 \pm 0.029$ & $0.043 \pm 0.006$ & $\mathrm{~S}$ & Metacentric \\
E3 & 0.289 & 0.313 & 0.602 & $0.520 \pm 0.016$ & $0.033 \pm 0.003$ & $\mathrm{~S}$ & Metacentric \\
F1 & 0.224 & 0.252 & 0.476 & $0.529 \pm 0.024$ & $0.026 \pm 0.003$ & $\mathrm{~S}$ & Metacentric \\
F2 & 0.000 & 0.654 & 0.654 & $1.000 \pm 0.000$ & $0.035 \pm 0.003$ & $\mathrm{~S}$ & Telocentric \\
X & 0.000 & 0.555 & 0.555 & $1.000 \pm 0.000$ & $0.030 \pm 0.003$ & $\mathrm{~S}$ & Telocentric \\
& 0.403 & 0.620 & 1.023 & $0.606 \pm 0.006$ & $0.055 \pm 0.005$ & $\mathrm{M}$ & Submetacentric \\
\hline
\end{tabular}

Remarks: $\mathrm{L}=$ large chromosome $(\mathrm{LT}>1.035), \mathrm{M}=$ medium chromosome $(\mathrm{LT}=0.798-1.035)$ and $\mathrm{S}=$ small chromosome $(\mathrm{LT}<0.798)$. 
Table 2. Mean of length short arm chromosome (Ls), length long arm chromosome (L1), length total arm chromosome (LT), relative length (RL) centromeric index (CI) and standard deviation (SD) of RL, CI from metaphase chromosome of 10 cells in the male jungle cat (Felis chaus Guldenstaedt, 1776) $2 n$ (diploid) $=38$

\begin{tabular}{cccccccc}
\hline \hline $\begin{array}{c}\text { Chromosome } \\
\text { pairs }\end{array}$ & Ls & L1 & LT & CI \pm SD & RL \pm SD & $\begin{array}{c}\text { Chromosome } \\
\text { size }\end{array}$ & $\begin{array}{c}\text { Chromosome } \\
\text { type }\end{array}$ \\
\hline A1 & 0.643 & 1.160 & 1.803 & $0.643 \pm 0.025$ & $0.093 \pm 0.009$ & $\mathrm{~L}$ & Submetacentric \\
A2 & 0.429 & 0.811 & 1.240 & $0.654 \pm 0.030$ & $0.064 \pm 0.004$ & $\mathrm{~L}$ & $\begin{array}{c}\text { Submetacentric } \\
\text { A3 }\end{array}$ \\
B1 & 0.376 & 0.731 & 1.107 & $0.660 \pm 0.032$ & $0.057 \pm 0.002$ & $\mathrm{~L}$ & Submetacentric \\
B2 & 0.311 & 1.207 & 1.518 & $0.795 \pm 0.023$ & $0.079 \pm 0.007$ & $\mathrm{~L}$ & Acrocentric \\
B3 & 0.280 & 0.982 & 1.262 & $0.778 \pm 0.027$ & $0.065 \pm 0.003$ & $\mathrm{~L}$ & Acrocentric \\
B4 & 0.281 & 0.815 & 1.167 & $0.784 \pm 0.052$ & $0.060 \pm 0.003$ & $\mathrm{~L}$ & Acrocentric \\
C1 & 0.779 & 0.846 & 1.091 & $0.742 \pm 0.040$ & $0.056 \pm 0.004$ & $\mathrm{~L}$ & Acrocentric \\
C2 & 0.516 & 0.615 & 1.131 & $0.544 \pm 0.021$ & $0.058 \pm 0.002$ & $\mathrm{~L}$ & Metacentric \\
D1 & 0.298 & 0.590 & 0.888 & $0.664 \pm 0.038$ & $0.046 \pm 0.006$ & $\mathrm{~S}$ & Submetacentric \\
D2 & 0.258 & 0.515 & 0.773 & $0.666 \pm 0.022$ & $0.040 \pm 0.003$ & $\mathrm{~S}$ & Submetacentric \\
D3 & 0.233 & 0.476 & 0.709 & $0.671 \pm 0.042$ & $0.037 \pm 0.004$ & $\mathrm{~S}$ & Submetacentric \\
D4 & 0.224 & 0.450 & 0.674 & $0.668 \pm 0.069$ & $0.035 \pm 0.003$ & $\mathrm{~S}$ & Submetacentric \\
E1 & 0.351 & 0.421 & 0.772 & $0.545 \pm 0.033$ & $0.040 \pm 0.005$ & $\mathrm{~S}$ & Metacentric \\
E2 & 0.289 & 0.326 & 0.615 & $0.530 \pm 0.025$ & $0.032 \pm 0.004$ & $\mathrm{~S}$ & Metacentric \\
E3 & 0.191 & 0.243 & 0.434 & $0.560 \pm 0.038$ & $0.022 \pm 0.005$ & $\mathrm{~S}$ & Metacentric \\
F1 & 0.000 & 0.662 & 0.662 & $1.000 \pm 0.000$ & $0.034 \pm 0.003$ & $\mathrm{~S}$ & Telocentric \\
F2 & 0.000 & 0.535 & 0.535 & $1.000 \pm 0.000$ & $0.028 \pm 0.003$ & $\mathrm{~S}$ & Telocentric \\
X & 0.355 & 0.625 & 0.980 & $0.638 \pm 0.024$ & $0.051 \pm 0.004$ & $\mathrm{M}$ & Submetacentric \\
Y & 0.133 & 0.215 & 0.348 & $0.618 \pm 0.018$ & $0.018 \pm 0.003$ & $\mathrm{~S}$ & Submetacentric \\
\hline
\end{tabular}

Remarks: $\mathrm{L}=$ large chromosome $(\mathrm{LT}>1.076), \mathrm{M}=$ medium chromosome $(\mathrm{LT}=0.902-1.076)$ and $\mathrm{S}=$ small chromosome $(\mathrm{LT}<0.902)$.

niques with Giemsa's (Rooney 2001, Campiranon 2003). Twenty cells of each individual chromosome checks, length measurements, karyotyping and idiograming were accomplished by using a light microscope as previously described (Chaiyasut 1989, Keawmad et al. 2007).

\section{Results}

Karyological study of the jungle cat using lymphocyte revealed that the chromosome number is $2 n$ (diploid) $=38$ and the fundamental number (NF) is 72 in male and female. The autosomes of the jungle cat composed of 6 types: A type had 6 large submetacentric chromosomes, B type had 8 large acrocentric chromosomes, $\mathrm{C}$ type had 4 large metacentric chromosomes, D type had 8 small submetacentric chromosomes, E type had 6 small metacentric chromosomes and F type had 4 small telocentric chromosomes. A pair of the short arm of chromosome E1 (chromosome pairs 14) showed a clearly observable satellite chromosomes. The X chromosome was a medium submetacentric chromosome and the Y chromosome was the smallest submetacentric chromosome (Figs. 2, 3, 4).

The important chromosome marker of the jungle cat is the asymmetrical karyotype, in which all 4 types of chromosomes are found (metacentric, submetacentric, acrocentric and telocentric chromosome). The data of the chromosomal checks on mitotic metaphase cells of the jungle cat are show in Tables 1 and 2. The largest and smallest chromosomes show large size difference (approximately 5 fold). The largest chromosome is submetacentric chromosome, while the second largest chromosome is acrocentric chromosome and the Y-chromosome is the smallest submetacentric chromosome (Figs. 2, 3, 4). The G-banding by the conventional and high-resolution technique revealed that the number of G-bands per haploid set, which includes autosomes, $\mathrm{X}$ and $\mathrm{Y}$ chromo- 

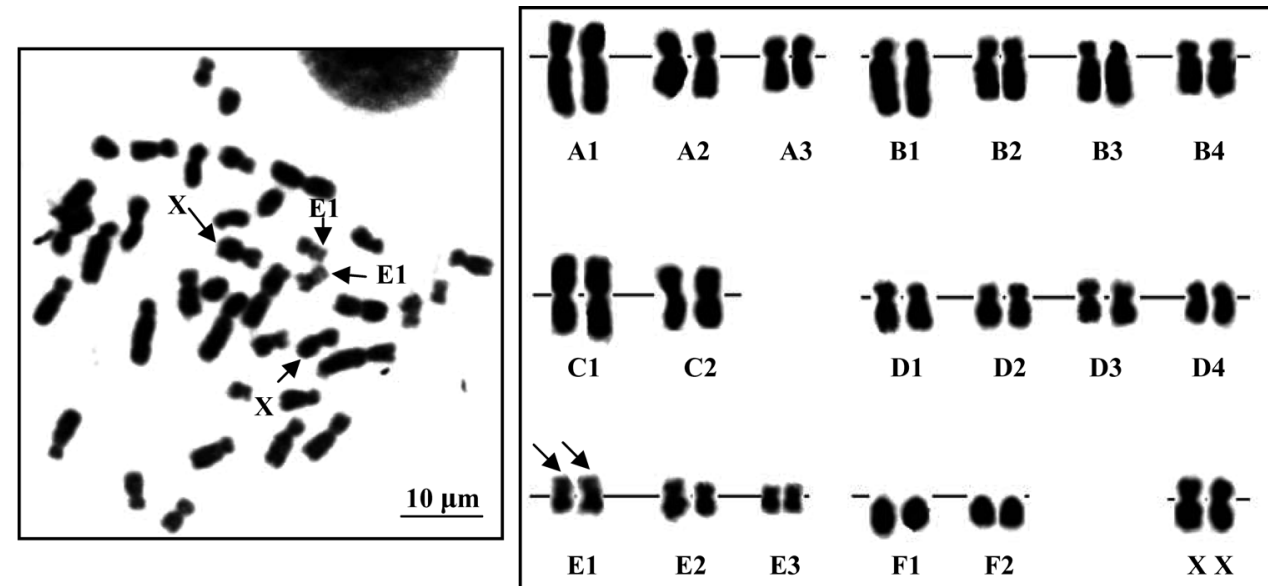

\section{A. Female of the jungle cat}
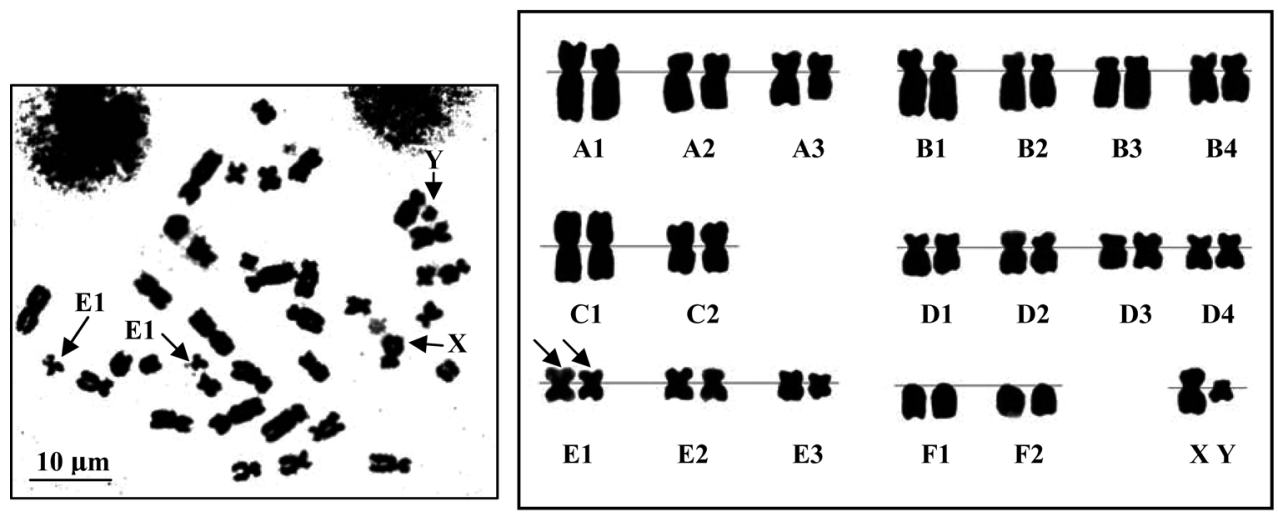

\section{B. Male of the jungle cat}

Fig. 2. Metaphase chromosome plates and karyotype of the female (A) and male (B) jungle cat (Felis chaus Guldenstaedt, 1776) $2 n$ (diploid) $=38$ by conventional staining technique, showing satellite chromosomes with nucleolar organizer regions, NORs (arrows).

somes, is 167 and 183, respectively (Figs. 5, 6).

Comparison of chromosome banding pattern between the jungle cat and the domestic cat (Felis catus) revealed that 7 chromosome pairs show the same pattern (pairs B1, B2, D1, D4, E3, F2 and X-chromosome) and 12 chromosome pairs share similarities (pairs A1, A2, A3, B3, B4, C1, C2, D2, E1, E2, F1 and Y-chromosome) (Fig. 7). This indicates that there is an evolutionary relationship between the jungle cat and the domestic cat. Figure 5 shows the idiogram for the jungle cat from the G-banding technique, while Figure 6 shows the idiogram from the high-resolution staining technique with landmarks, bands and sub-bands. The karyotype formula for the jungle cat is as follows: $2 n(38)=\mathrm{L}_{4}{ }^{\mathrm{m}}+\mathrm{L}_{6}{ }^{\mathrm{sm}}+\mathrm{L}_{8}{ }^{\mathrm{a}}+\mathrm{S}_{6}{ }^{\mathrm{m}}+\mathrm{S}_{8}{ }^{\mathrm{sm}}+\mathrm{S}_{4}^{\mathrm{t}}+$ sex chromosomes. 

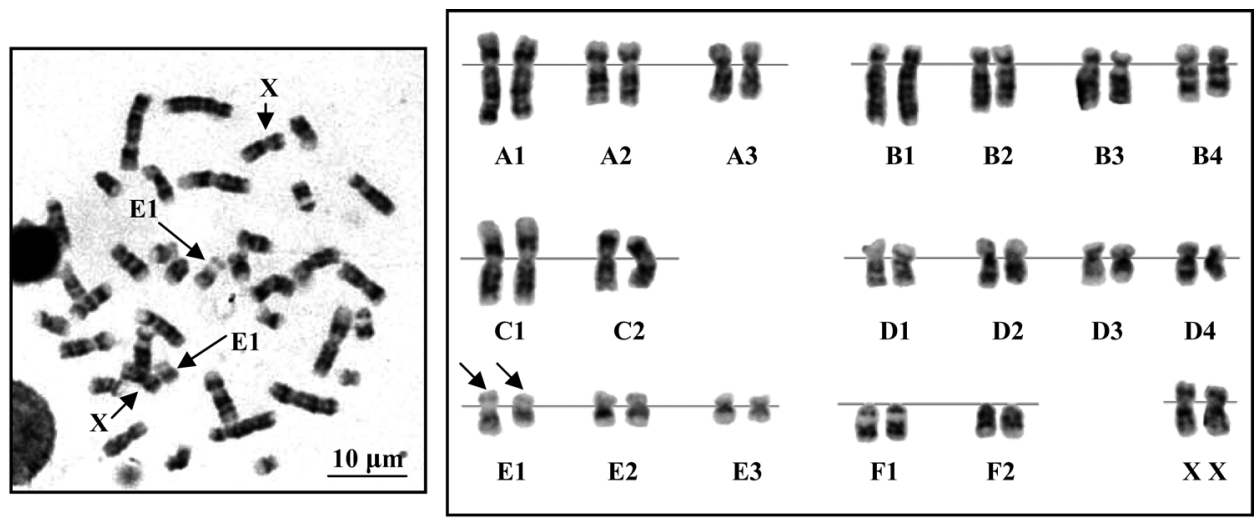

\section{A. Female of the jungle cat}
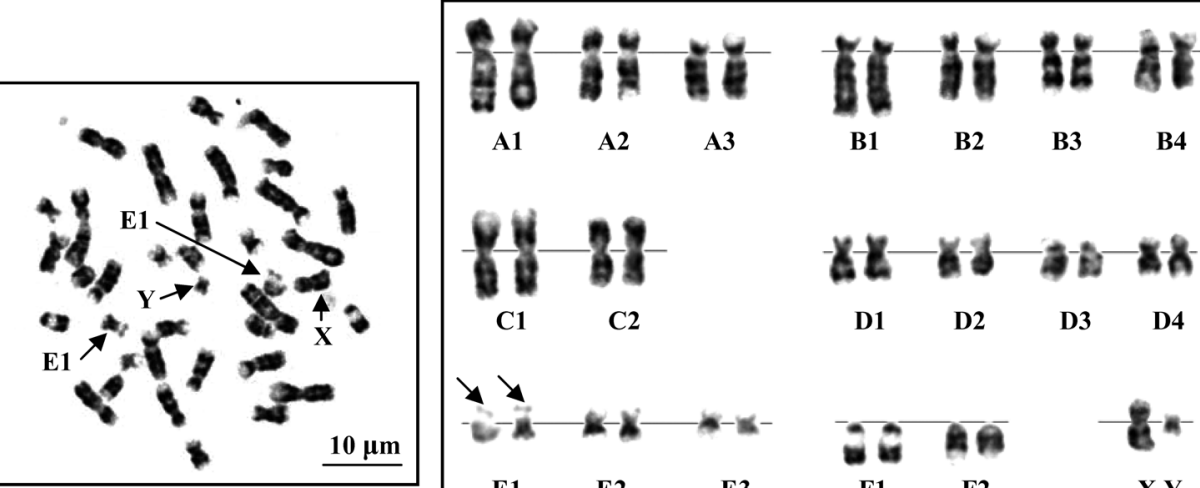

A1

A2 A3
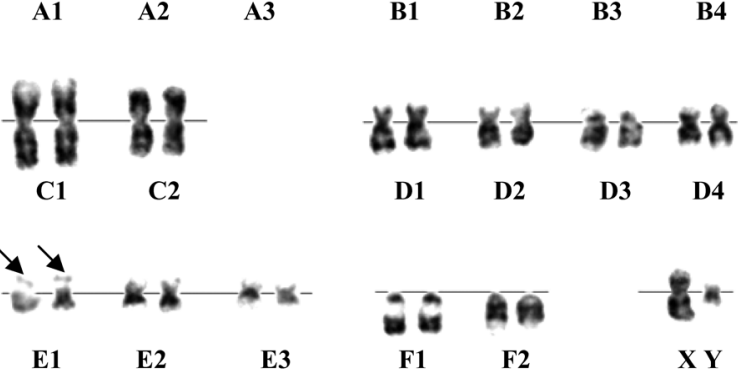

\section{B. Male of the jungle cat}

Fig. 3. Metaphase chromosome plates and karyotype of the female (A) and male (B) jungle cat (Felis chaus Guldenstaedt, 1776) $2 n$ (diploid) $=38$ by G-banding technique, showing satellite chromosomes with nucleolar organizer regions, NORs (arrows).

\section{Discussion}

Karyological study of the jungle cat using lymphocyte culture revealed that the chromosome number is $2 n=38$. This result agrees with the previous studies by Wurster-Hill and Gray (1973) indicating that a member of the jungle cat family has $2 n=38$. This corresponds to $2 n$ for the member of the family Felidae according to reports in puma (Felis concolor), Canadian lynx (F. lynx), snow leopard (Uncia uncia), jaguarondi (F. yagouaroundi), cheetah (Acinonyx jabatus jabatus), serval (F. serval), fishing cat (F. viverrina), Asian leopard cat (Prionallurus bengalensis), bob cat (Lynx rufus), marbled cat (F. marmorata), European wild cat (F. silvestris), black footed cat (F. nigripes), leopard (Panthera pardus), tiger (P. tigris), domestic cat (F. catus) and ocelot (F. pardalis) (Makino and Tateishi 1952, Thuline and Norby 1961, Hsu 1962, Hsu et al. 1963, Hsu and Rearden 1965, Ohno et al. 1962, Matano 1963, Chu et al. 1964, Benirschke and Low 1966, Leyhausen and Tonkin 1968, Sutton 1968, Hard 1968, Wurster and Benirschke 1967, 1968a, 1968b, Wurster 1969, Milosevic et al. 1972, Wurster-Hill and Meritt 1974, Keawmad et al. 2007). However this number differs 


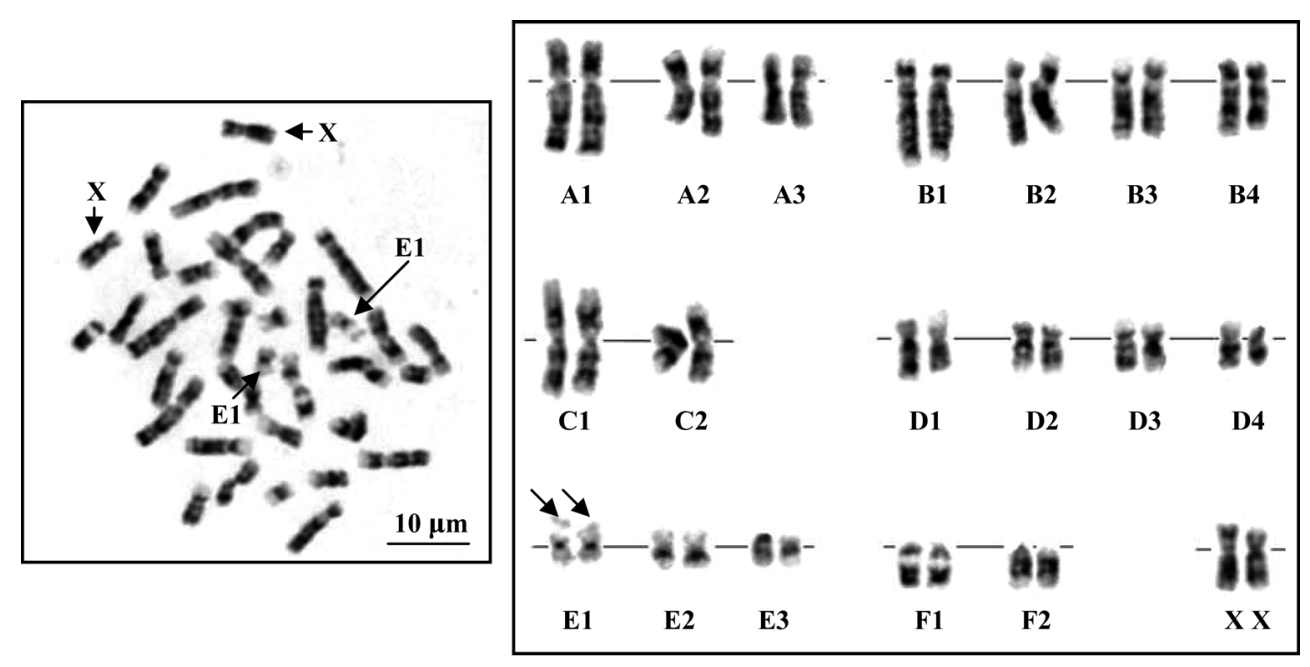

A. Female of the jungle cat

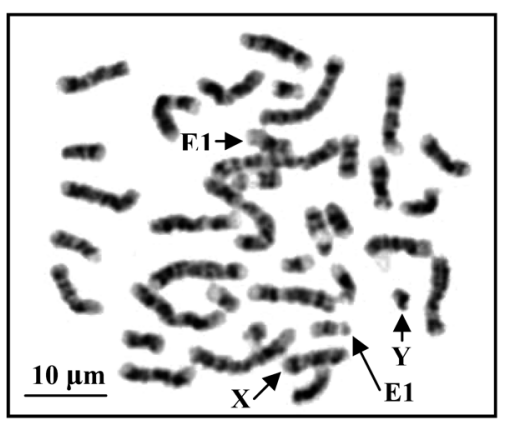

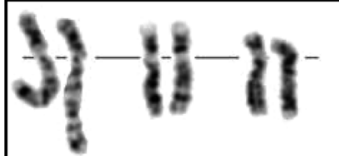
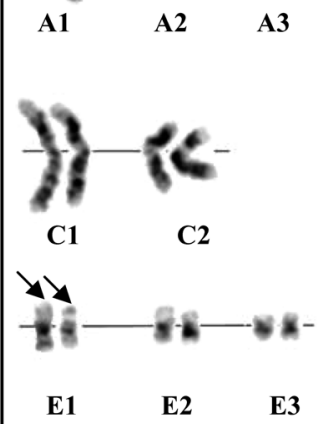
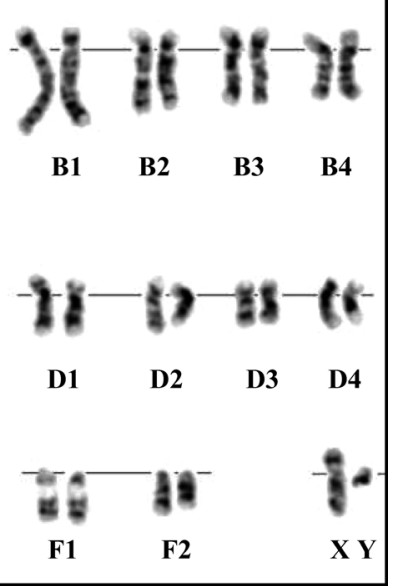

\section{B. Male of the jungle cat}

Fig. 4. Prometaphase chromosome plates and karyotype of the female (A) and male (B) jungle cat (Felis chaus Guldenstaedt, 1776) $2 n$ (diploid) $=38$ by high-resolution staining technique, showing satellite chromosomes with nucleolar organizer regions, NORs (arrows).

from the chromosome number of Geoffroy's ( $F$. geoffroyi) and Marguay ( $F$. wiedi) which is $2 n=36$ (Hsu 1962, Hsu et al. 1963a).

The autosomes of the jungle cat can be separated to 6 types: A type has 6 large submetacentric chromosomes, B type has 8 large acrocentric chromosomes, $\mathrm{C}$ type has 4 large metacentric chromosomes, D type has 8 small submetacentric chromosomes, E type has 6 small metacentric chromosomes and $\mathrm{F}$ type has 4 small telocentric chromosomes. The result agrees with the previous studies by Wurster-Hill and Gray (1973) indicating that a member of the jungle cat family had 6 types of 

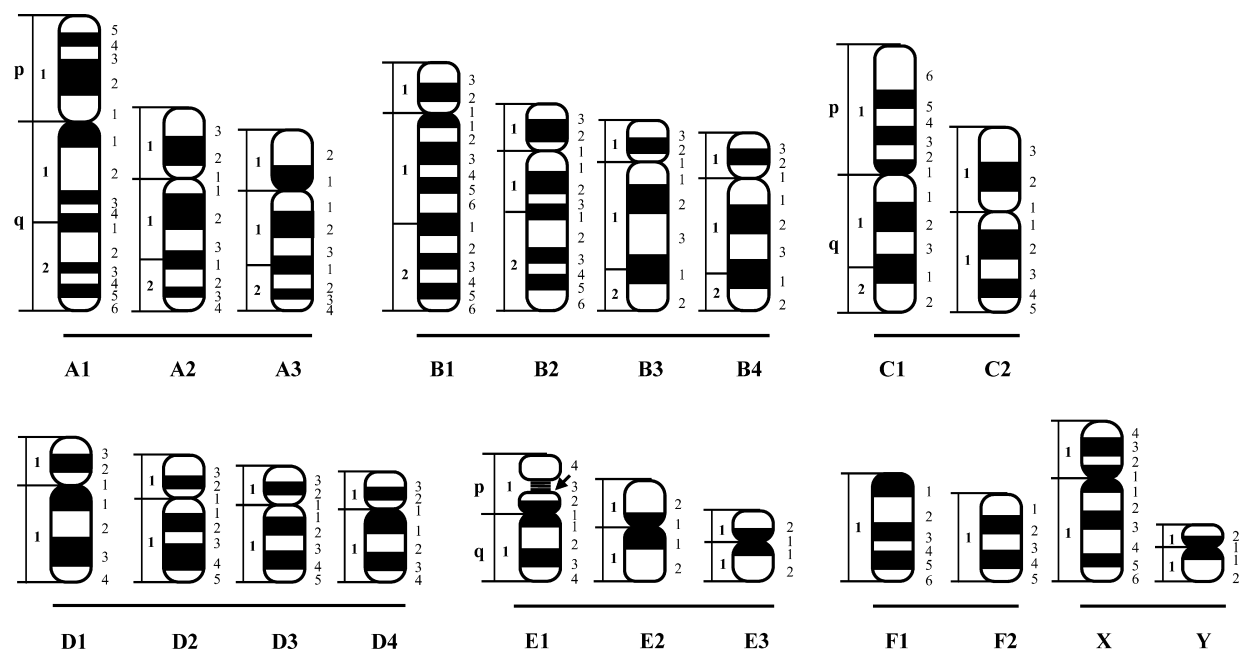

Fig. 5. Idiogram of the jungle cat (Felis chaus Guldenstaedt, 1776) $2 n$ (diploid) $=38$ by G-banding technique. The arrow indicates nucleolar organizer region (NOR).

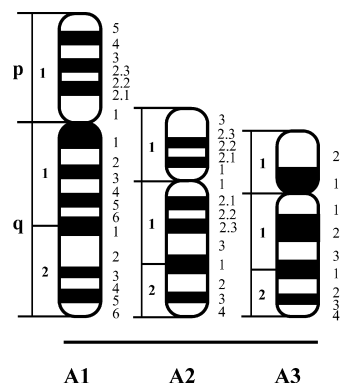

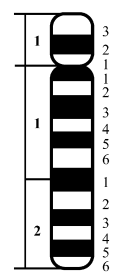
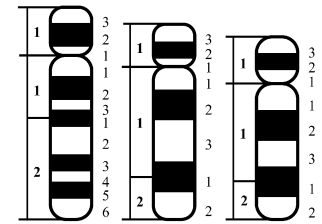

B1
B2

B3
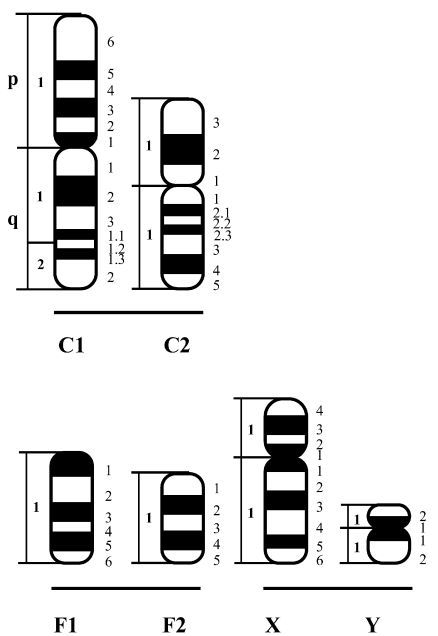
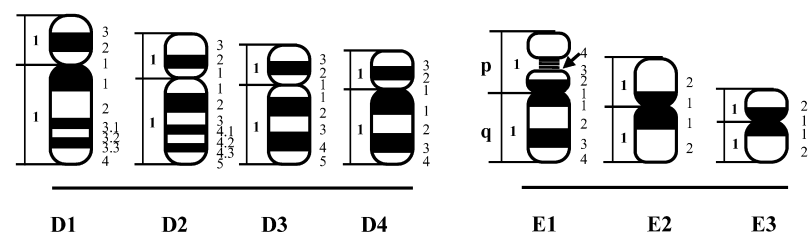

Fig. 6. Idiogram of the jungle cat (Felis chaus Guldenstaedt, 1776) $2 n$ (diploid) $=38$ by high-resolution technique. The arrow indicates nucleolar organizer region (NOR).

autosome: A type had 6 submetacentric chromosomes, B type had 8 acrocentric chromosomes, C type had 4 metacentric chromosomes, D type had 8 submetacentric chromosomes, E type had 6 metacentric chromosomes and $\mathrm{F}$ type had 4 telocentric chromosomes.

The NF of the jungle cat is 72 in male and female. For the sex-chromosomes, the X chromosome was medium submetacentric chromosome and the $\mathrm{Y}$ chromosome was smallest submetacentric chromosome. This result agrees with the previous studies by Wurster-Hill and Gray (1973). The comparison of the jungle cat $\mathrm{X}$ and $\mathrm{Y}$ chromosomes to those of the domestic cat indicated that the $\mathrm{X}$ chromosome was the medium submetacentric chromosome and the $\mathrm{Y}$ chromosome was the smallest submetacentric chromosome (Thuline and Norby 1961, Ohno et al. 1962, Matano 1963, Chu et al. 1964, Hsu and Rearden 1965). The comparison of the jungle cat X and Y chromosome to 


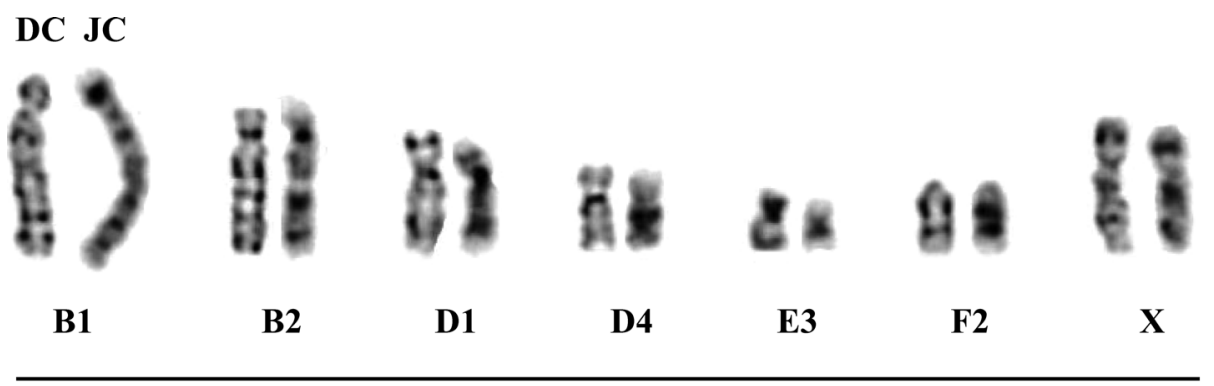

A
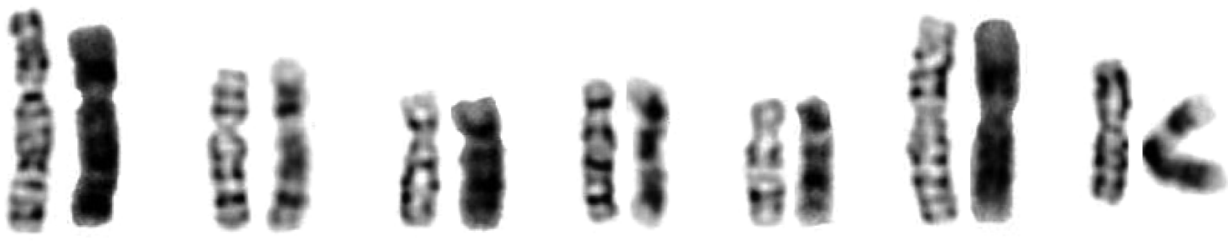

A1

A2

A3

B3

B4

C1

C2
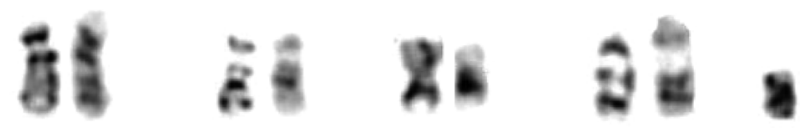

D2

E1

E2

F1

Y

B

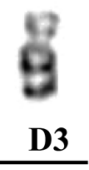

Domestic cat

\section{C}

Jungle cat

D3

Fig. 7. A comparison of the chromosome of animal species in the family Felidae in Thailand, between domestic cat, Felis catus (DC, left) (Nie et al. 2002) and jungle cat, (Felis chaus Guldenstaedt, 1776) (JC, right) in this study, showing the same (A), similar (B) and different (C) by G-banding patterns.

animals in family Felidae in Thailand namely, leopard (P. pardus) found that X and Y chromosome were submetacentric and subtelocentric chromosomes (Hsu et al. 1963) and clouded leopard (Pardofelis nebulosa) found that $\mathrm{X}$ and $\mathrm{Y}$ chromosomes were submetacentric chromosomes in this species (O’Brien et al. 2006).

From this study, the jungle cat had the chromosome marker at the short arm of chromosomes E1 (chromosome pairs 14) that was a satellite chromosomes with nucleolar organizer regions (NORs). This result agrees with previous reports about the chromosomes E1 of animals in the family Felidae having a satellite chromosomes (Makino and Tateishi 1952, Thuline and Norby 1961, Hsu 1962, Hsu et al. 1963, Hsu and Rearden 1965, Ohno et al. 1962, Matano 1963, Chu et al. 
1964, Benirschke and Low 1966, Leyhausen and Tonkin 1968, Sutton 1968, Hard 1968, Wurster and Benirschke 1967, 1968a, 1968b, Wurster 1969, Milosevic et al. 1972, Wurster-Hill and Meritt 1974, Keawmad et al. 2007).

The G-banding by the conventional and high-resolution staining techniques revealed that the number of G-bands on one set of haploid, which includes autosomes, X and Y chromosomes, is 167 and 183, respectively. In a domestic cat, there are 317 bands on one set of haploid chromosomes (Yang et al. 2000). Our present study showed a lower number of bands compared with previous studies because only clearly observable bands of the chromosomes were counted.

Comparison of chromosome banding patterns between the jungle cat and the domestic cat (Nie et al. 2002) revealed that seven chromosome pairs show the same patterns (pairs B1, B2, D1, D4, E3, F2 and X chromosome) and twelve pairs share similarities (pairs A1, A2, A3, B3, B4, C1, C2, $\mathrm{D} 2, \mathrm{E} 1, \mathrm{E} 2, \mathrm{~F} 1$ and $\mathrm{Y}$ chromosome). This indicates that there is evolutionary relationship between the jungle cat and the domestic cat. For further studies, more information about genetic differences is needed which may be accomplished by using molecular biology or molecular genetics.

\section{Acknowledgements}

The financial support from The Zoological Park Organization under the Royal Patronage of H.M. the King is gratefully acknowledged. We also thank Mr. Sopon Dumnui, Director of the organization, Dr. Sumat Kamolnaranath, Chief of the Educational Division and Director of Songkhla Zoo, for valuable help.

\section{References}

Benirschke, K. and Low, R. J. 1966. Chromosome studies of four carnivores. Mammalian Chromosome Newsletter 21: 148-160.

Campiranon, A. 2003. Cytogenetics. 2nd ed. Department of Genetics, Faculty of Science, Kasetsart University, Bangkok, Thailand.

Chaiyasut, K. 1989. Cytogenetics and cytotaxonomy of the family Zephyranthes. Department of Botany, Faculty of Science, Chulalongkorn University, Bangkok, Thailand.

Chu, E. H. Y., Thuline, H. C. and Norby, D. E. 1964. Triploid-diploid chimerism in a male tortoiseshell cat. Cytogenetics 3: $1-8$.

Hard, W. L. 1968. The karyotype of a male cheetah, Acinonyx jabatus jabatus. Mammalian Chromosome Newsletter 9: $16-25$.

Hsu, T. C. 1962. Two species of cats with 36 chromosomes. Mammalian Chromosome Newsletter 8: 4-10.

-, Arrighi, F. E. and Luquette, G. F. 1963. Karyological studies of nine species of Felidae. Am. Nat. 97: $225-232$.

— and Rearden, H. H. 1965. Further karyological studies on Felidae. Chromosoma (Berl.) 16: 365-371.

Keawmad, P., Tanomtong, A. and Khunsoon, S. 2007. A study on karyotype of the Asian leopard cat, Prionailurus bengalensis (Carnivora, Felidae) by Conventional staining, G-banding and high-resolution technique. Cytologia 72: $101-110$.

Lekagul, B. and McNeely, J. A. 1977. Mammals of Thailand. 1nded. Kurusapha Ladprao Press, Bangkok, Thailand.

— and - 1988. Mammals of Thailand. 2nded. Sahakarn Bhaet, Bangkok, Thailand.

Leyhausen, P. and Tonkin, B. A. 1968. Comment on the karyotypes of the leopard cat and fishing cat. Mammalian Chromosome Newsletter 9: 78-85.

Makino, S. and Tateishi, S. 1952. A comparison of the chromosomes of the lion, Chinese leopard cat and house cat. J. Morphol. 90: 93-99.

Matano, Y. 1963. A study of the chromosome in the cat. Japan Journal Gene. 38: 147-152.

Milosevic, M., Zivkovic, S. and Isakovic, I. 1972. Hromozomske karakteristike nekin carnivore Iz Srbij. Genetika (Beogard) 4: 1-9.

Nie, W., Wang, J., O’Brien, P. C. M., Fu, B. and Ying, T. 2002. The genome phylogeny of domestic cat, red panda and mustelid species revealed by comparative chromosome paining and G-banding. Chromo. Res. 10: 209-222.

O'Brien, S. J., Menninger, J. C. and Nash, W. G. 2006. Atlas of Mammalian Chromosome. Wiley-Liss, United States of America. 
Ohno, S., Stenius, C., Weiler, C. P., Trujillo, J. M., Kaplan, W. D. and Kinosita, R. 1962. Early meiosis of male germ cells in fetal testis of Felis domestica. Exp. Cell Res. 27: 401-410.

Par, J., Komonpalin, K. and Wongkarasin, M. 2003. Mammals of Thailand. Sarakadee Press, Bangkok, Thailand.

Rooney, D. E. 2001. Human cytogenetics: constitutional analysis. Oxford University Press: Oxford, UK.

Sutton, D. A. 1968. Karyotype of a female bob cat, Lynx rufus californicus. Mammalian Chromosome Newsletter 9: 249-254.

Thuline, H. and Norby, D. E. 1961. Spontaneous occurrence of chromosome abnormality in cat. Science 134: 544-546.

Wurster, D. H. and Benirschke, K. 1967. Chromosome number in thirty species of Canivora. Mammalian Chromosome Newsletter 8: 195-216.

— and - 1968a. Comparative cytogenetic studies in the order Canivora. Chromosoma 24: 336-382.

— and - 1968b. Karyotype of four more species of cats. Mammalian Chromosome Newsletter 9: 236-245.

- 1969. Cytogenetic and phylogenetic studies in Carnivora. In: Comparative mammalian cytogenetics. Benirschke, K., ed., Springger-Verlag, N.Y.

Wurster-Hill and Gray 1973. Chromosome of eight species from five families of Carnivora. Journal Mammalian 54: $763-782$.

Wurster-Hill and Meritt, D. A., Jr. 1974. The G-band chromosomes of the marbled cat, Felis marmorata. Mammalian Chromosome Newsletter 15: 14-19.

Yang, F., Graphodatsky, A. S., O’Brien, P. C. M., Colabella, A., Solanky, N., Squire, M., Sargan, D. R. and Ferguson-Smith, M. A. 2000. Reciprocal chromosome paining illuminates the history of genome evolution of the domestic cat, dog and human. Chromo. Res. 8: 393-404. 